\title{
Sequence Variability, Recombination Analysis, and Specific Detection of the W Strain of Plum pox virus
}

\author{
Miroslav Glasa, Tadeusz Malinowski, Lukáš Predajňa, Neda Pupola, \\ Dzintra Dekena, Lech Michalczuk, and Thierry Candresse
}

First and third authors: Institute of Virology, Department of Plant Virology, Slovak Academy of Sciences, Dúbravská cesta 9, 84505 Bratislava, Slovakia; second and sixth authors: Research Institute of Pomology and Floriculture, Pomologiczna 18, 96-100 Skierniewice, Poland; fourth author: Latvia State Institute of Fruit-Growing, Graudu str. 1, Dobele, LV-3701, Latvia; fifth author: Pure Horticultural Research Centre, Abavas iela 2, Pure, Tukuma novads, LV-3124, Latvia; and seventh author: UMR GDPP, INRA, Université Bordeaux 2, Centre INRA de Bordeaux, BP 81, 33883 Villenave d'Ornon Cedex, France.

Accepted for publication 16 March 2011.

\begin{abstract}
Glasa, M., Malinowski, T., Predajňa, L. Pupola, N., Dekena, D. Michalczuk, L., and Candresse, T. 2011. Sequence variability, recombination analysis, and specific detection of the W strain of Plum pox virus. Phytopathology 101:980-985.

Plum pox virus (PPV), a member of the genus Potyvirus, is the causal agent of Sharka, the most detrimental disease of stone-fruit trees worldwide. PPV isolates are grouped into seven distinct strains. The minor PPV-W strain was established recently for the divergent W3174 isolate found in Canada. Here, the partial or complete genomic sequences of four PPV-W isolates from Latvia have been determined. The completely sequenced isolates LV-141pl and LV-145bt share 93.1 and 92.1\% nucleotide identity, respectively, with isolate W3174, with two regions of higher (>20\%) divergence in the P1/HC-Pro and NIa (VPg) regions. Further analyses demonstrated that these two regions correspond
\end{abstract}

ABSTRACT to two independent recombination events in the W3174 genome, one involving PPV-M (approximate genome positions 692 to 1424) and the other PPV-D (nucleotides 5672 to 5789). The LV-141pl and LV-145bt isolates appear to be representatives of the "ancestral" PPV-W strain, not affected by recombination. The PPV-W intrastrain variability is substantially higher than that of all other PPV strains, with potential implications for the serological detection of PPV-W isolates. A PPV-Wspecific primer pair has been developed, allowing the specific reversetranscription polymerase chain reaction detection of all five presently available $\mathrm{W}$ isolates. The characterization of these new PPV-W isolates sheds light on PPV-W evolutionary history, further supports the hypothesis of its East-European origin, and opens the way for the biological and epidemiological characterization of this poorly known PPV strain.

Additional keywords: diversity, Winona.
Plum pox virus (PPV), a member of the genus Potyvirus, is the causal agent of Sharka, considered to be the most detrimental viral disease of Prunus spp. worldwide, including economically important stone fruit crops (peach, apricot, plum, and Japanese plum) (2,10). Viral particles contain a single-stranded genomic RNA of positive polarity (9,741 to 9,795 nucleotides in length) encapsidated by a single type of capsid protein subunit. The genomic organization is typical of Potyvirus spp., with a major open reading frame encoding a large polyprotein precursor $(3,125$ to 3,143 amino acids, $\approx 355 \mathrm{kDa}$ ) that is proteolytically processed by three virus-encoded proteinases (P1-Pro, HC-Pro, and NIaPro) to yield as many as 10 mature functional proteins $(18,32)$.

On the basis of serological and molecular differences, seven PPV strains are now recognized. From those, PPV-M, -D, and Rec are the most widespread $(3,4)$ while the four additional minor strains have a much more limited prevalence or geographical distribution. These are the El Amar (EA) (35) and Turkey (T) (28) strains, so far reported only from Egypt and Turkey respectively; the Cherry strain, that is uniquely able to naturally infect cherry in

Corresponding author: M. Glasa; E-mail address: Miroslav.Glasa@savba.sk

The nucleotide sequences reported here have been deposited in the GenBank database under accession numbers HQ670745 to HQ670748.

* The $\boldsymbol{e}$-Xtra logo stands for "electronic extra" and indicates that the online version contains one supplemental figure and one supplemental table.

doi:10.1094/PHYTO-12-10-0334

(C) 2011 The American Phytopathological Society addition to other more typical Prunus hosts (PPV-C) (23); and the Winona (W) strain, so far characterized only from a backyard plum tree identified in Canada during PPV eradication efforts (14).

Genetic variability is an essential feature of RNA viruses, which are characterized by high mutation rates resulting from the lack of proofreading activity of their RNA-dependent RNA polymerases $(7,9)$. In addition, RNA recombination has been shown to represent another evolutionary mechanism shaping the populations of RNA viruses and contributing to their diversity $(27,35)$. Both processes can lead to the emergence of new viral strains and variants better adapted to the ever-changing environmental conditions or with an increased fitness in their natural hosts $(8,21)$.

In the particular case of Potyvirus spp., the contribution of recombination to the evolutionary history of a number of viruses has been clearly established (25). Despite the early discovery of the recombinant PPV-o6 isolate (5), recombination was for a long time considered as a marginal force in PPV evolution. However, the improvement of techniques for the detection of recombination events $(24,33)$ and the increased availability of sequence data changed this view in recent years. Indeed, recombination appears today to have played a major role in the evolutionary history of PPV. Both the PPV-Rec and PPV-T strains are, in fact, ensembles of isolates sharing unique recombination events $(12,28)$. In addition, an ancient recombination event affecting the $5^{\prime}$ part of the genome of the PPV-D or PPV-M strains has also been identified (13) and a putative recombination event in the P1/HC-Pro region of the only known isolate of the $\mathrm{W}$ strain, W3174, was also 
reported (22). Therefore, four of the seven known PPV strains have one or more recombination events in their evolutionary history.

The understanding of the genetic variability of PPV populations is an important prerequisite for an efficient diagnosis, management, and long-term control of the Sharka disease. Similar to the PPV-EA and -C strains, the $\mathrm{W}$ strain is highly divergent from the major D, M, and Rec strains (14) but the availability of a single PPV-W isolate has, thus far, completely hampered the analysis of the genetic variability of this strain or the delineation of common properties characterizing its isolates.

In the present work, the complete genome sequence of two PPV-W isolates was determined, together with partial sequences of two additional isolates. The comparisons performed with the sequence of the W3174 isolate and with other available PPV sequences demonstrate an unexpectedly high genetic diversity within the PPV-W strain and shed new light on its evolutionary history.

\section{MATERIALS AND METHODS}

Virus isolates. The isolates LV-140pl, LV-141pl, LV-143pl, and LV-145bt were collected from infected plum (pl, Prunus domestica) and from a blackthorn (bt, P. spinosa) hybrid in Latvia in spring 2010. The trees displayed typical Sharka symptoms (yellow rings on leaves). All infected trees, $\approx 20$ years old, were planted in a varietal collection orchard of the Pure Horticultural Research Station (Pure, Latvia). The corresponding plant materials had originally been obtained from former Soviet Union states.

Full-length sequencing of $\mathrm{LV}-141 \mathrm{pl}$ and $\mathrm{LV}-145 \mathrm{bt}$ isolates. Complete genome sequence of the LV-141pl and LV-145bt isolates was obtained by the primer walking method using either common PPV primers (13) or newly designed primers based on the W3174 sequence (Supplementa1 Table 1). In total, eight overlapping polymerase chain reaction (PCR) fragments spanning the whole genome were amplified using TaKaRa Ex Taq polymerase (TaKaRa, Bio Inc.) and PCR products were directly sequenced as previously described (13). When necessary, the viral sequence was verified by independent PCR amplification and sequencing using custom-made primers.

Partial genomic sequencing of additional PPV-W isolates. PCR fragments were amplified from purified total nucleic acid extracts prepared from original infected Prunus spp. leaves using the NucleoSpin RNA Plant kit (Macherey-Nagel). cDNAs were synthesized using the AMV reverse transcriptase and random hexamer primers (both from Promega Corp.). An $\approx 720$-bp fragment spanning the $\mathrm{C}$-terminal (C-ter) $\mathrm{NIb} / \mathrm{N}$-terminal (N-ter) capsid protein $(\mathrm{CP})$ region was amplified using the TaKaRa Ex Taq polymerase (TaKaRa, Bio Inc.) and primer pair NCuniFor 5'GAGGCAATTTGTGCTTCAATGG-3' (sense) and NCuniRev 5'CGCTTAACTCCTTCATACCAAG-3' (antisense).

In addition, $\approx 1.4$-kb fragments spanning the $\mathrm{P} 1 / \mathrm{HC}$-Pro region or the $\mathrm{C}$-ter $\mathrm{CI} / 6 \mathrm{~K} 2 / \mathrm{N}$-ter NIa region were similarly amplified using primer pairs LV491F/LV1979R and LV4732F/LV6254R, respectively (for sequence of primers see Supplemental Table 1). All PCR products were purified using the Wizard SV Gel and PCR Clean-up System (Promega Corp.) and directly sequenced on both strands using either the PCR primers or specific internal primers, using an automated DNA sequencer (ABI 3130xl Genetic Analyser; Applied Biosystems).

Sequence analyses. Partial sequences were compared with the sequences available in the GenBank database (www.ncbi.nlm.nih.gov). Sequence analyses were performed using the Molecular Evolutionary Genetics Analysis (MEGA v.4.1) and DNA Sequence Polymorphism (DnaSP v.5) softwares $(15,17)$. The phylogenetic trees were inferred using the neighbor-joining algorithm implemented in MEGA. The distance metrics used were the Kimura's two-parameter method and a p-distance strict identity model for nucleotide and amino acid sequence analyses, respectively. Putative recombination signals in complete genomic sequences were detected using PHYLPRO v. 1.0 (33), which displays graphically the coherence of sequence relationships (phylogenetic correlation) over the entire length of a set of aligned homologous sequences.

Specific reverse-transcriptase PCR detection of PPV-W isolates. For the specific detection of PPV-W isolates, a two-step reverse-transcriptase (RT)-PCR protocol (12) was used. Briefly, cDNA was synthesized using pdN6 primers and AMV reverse transcriptase (both from Promega Corp.) either from total RNA (NucleoSpin RNA Plant kit; Macherey-Nagel) or immunocaptured viral particles (anti-PPV immunoglobulin G AS196 kindly obtained from Dr. G. Labonne, INRA, Montpellier, France). An aliquot of cDNA was added to PCR reactions containing EmeraldAmp GT PCR Master Mix (TaKaRa, Bio Inc.) and PPV-W specific primers W8328F (5'-GCATCAATGG TAGAGGCATG-3', sense) and W8711R (5'-CATTGACGTT GTGCTCTGCA-3', antisense), targeting the $3^{\prime} \mathrm{NIb}-5^{\prime} \mathrm{CP}$ region (nucleotide positions 8328 to 8714 on the W3174 and LV141pl genomes and 8328 to 8711 on the LV145bt genome).

The P1 and P2 universal primers (34) were used in a parallel PCR to confirm the presence of PPV in all tested samples. For both primer sets, the same cycling conditions were used: denaturation at $98^{\circ} \mathrm{C}$ for $1 \mathrm{~min}, 35$ cycles of amplification $\left(98^{\circ} \mathrm{C}\right.$ for $10 \mathrm{~s}, 62^{\circ} \mathrm{C}$ for $30 \mathrm{~s}$, and $72^{\circ} \mathrm{C}$ for $30 \mathrm{~s}$ ), and a final extension at $72^{\circ} \mathrm{C}$ for $5 \mathrm{~min}$. All PCR products were analyzed by nondenaturing electrophoresis in $1 \%(\mathrm{p} / \mathrm{vol})$ agarose gels and GoldView (Guangzhou Geneshun Biotech) staining.

\section{RESULTS}

To examine the actual genetic diversity of PPV around the world, field surveys and sampling were performed in a number of countries in 2008 to 2010 in the frame of the SharCo EU FP7 project (http://www.sharco.eu/sharco/). Four PPV isolates collected in Latvia (LV-140pl, LV-141pl, LV-143pl, and LV-145bt) were determined as belonging to the PPV-W strain based on partial nucleotide sequencing and on serological analysis (T. Malinowski, unpublished data). Sequence comparisons for a short $\mathrm{PCR}$ fragment spanning the $\mathrm{C}$-ter $\mathrm{NIb} / \mathrm{N}$-ter $\mathrm{CP}$ region (nucleotide positions 8334 to 9054 of the genome, accession numbers HQ670745 to HQ670748) showed nucleotide identity levels with the W3174 isolate (AY912055) of 91.0, 92.4, 92.5, and $92.8 \%$ for LV-145bt, LV-140pl, LV-143pl, and LV-141pl, respectively (corresponding amino acid identities were 92.5 to 92.9\%). Nucleotide and amino acid sequence identities with all other PPV isolates, regardless of the strain to which they belong, were $<73 \%$.

A phylogenetic tree generated from these partial genomic sequences and those of $85 \mathrm{PPV}$ isolates retrieved from the GenBank database confirmed this analysis and unambiguously assigned the LV-140pl, LV-141pl, LV-143pl, and LV-145bt isolates to a common PPV-W cluster with isolate W3174, with $100 \%$ bootstrap support. This analysis pinpointed also that Latvian isolates form two various subclusters, represented by LV-145bt alone and by LV-140pl, LV-141pl, and LV-143pl.

Because the only complete genomic sequence available for the PPV-W strain was that of isolate W3174 (AY912055), the complete genomic sequences of LV-141pl and LV-145bt were determined in order to shed further light onto PPV-W intrastrain variability. The genomic RNA of LV-141pl and LV-145bt (accession numbers HQ670746 and HQ670748) is composed of 9,789 and 9,786 nucleotides (nt), respectively, excluding the poly(A) tail. Both genomes have an organization similar to that reported for all other previously characterized PPV isolates. As compared with W3174 and the newly sequenced isolates LV-140pl, LV- 
141pl, and LV-143pl, isolate LV-145bt shows a 3-nt deletion at positions 8604 to 8606 of the genome (N-terminal part of the $\mathrm{CP}$ gene) and a 1-nt insertion at position 9,754 in the $3^{\prime}$ noncoding region. The large open reading frame of LV-145bt is $9,420 \mathrm{nt}$ long $(9,423$ in $\mathrm{LV}-141 \mathrm{pl})$ and encodes a polyprotein of 3,140 amino acids $(3,141$ in $\mathrm{LV}-141 \mathrm{pl})$ with a calculated $\mathrm{Mr}$ of $355.9 \mathrm{kDa}$ (355.6 kDa in LV-141pl). All motifs characteristic of potyviral proteins are conserved in the genomes of these two isolates, including the $\mathrm{KITC}^{360-363}$ (numbering according to the LV-145bt sequence) and PTK ${ }^{618-620}$ motifs (32) associated with aphid transmission in the HC-Pro, and the $\mathrm{DAG}^{2821-2823}$ tripeptide also involved in aphid transmission (1) in the N-terminus of the CP (Fig. 1). The predicted molecular mass of the LV-141pl and LV145bt CP is 36,438 and 36,403, respectively. Comparison of the $\mathrm{CP}$ N-terminal hypervariable sequences (Fig. 1) and phylogenetic analysis using the $\mathrm{C}$-ter $\mathrm{NIb} / \mathrm{N}$-ter $\mathrm{CP}$ region (Supple-

\begin{tabular}{|c|c|}
\hline $\mathrm{LV}-145 \mathrm{bt}$ & ANEEDDDST-VPAGRPALPATTPPTTTTAPQVTATSTQSLQSTTSMFNPVFTPATTQPSI \\
\hline $\mathrm{LV}-140 \mathrm{pl}$ & 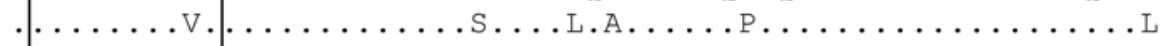 \\
\hline $\mathrm{LV}-141 \mathrm{pl}$ & 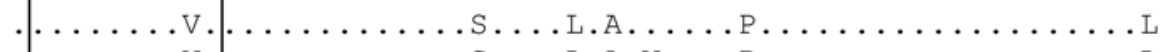 \\
\hline 7-143pl & 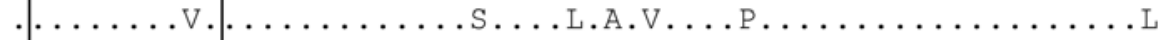 \\
\hline 3174 & 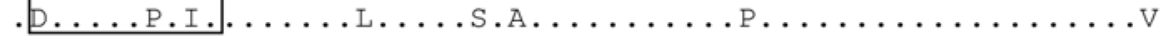 \\
\hline PENN-1 & .D.RE.E-EE . . . K. IVVTA-.AA.SPIL.PPPVIQPAPRT.AP.L. .I . . . . . A AT \\
\hline PS & .D.RE . .EE . . . . TVVTA-.AA.VATT.PAPVIQPAP.T.AP . . . I . . . . . AV \\
\hline OR-3 & 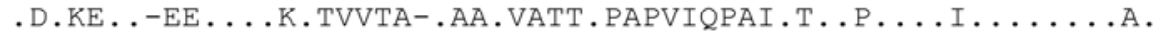 \\
\hline $\mathrm{AbTk}$ & .D.KE. . -EE.G..K.IVVTA-.AA.VATT.PAPLIQPAP.T.APT . . I . . . . . . AT \\
\hline EA & 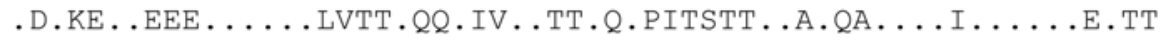 \\
\hline ot & KPSTSATTN-PTSFGVIGNESVAPSSSNTLANLGRDRDVDAGSIGTFTVPRLKAMTSKLS \\
\hline pl & 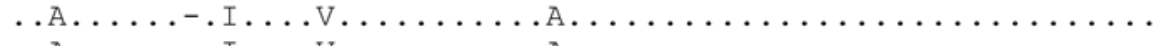 \\
\hline LV-14] & 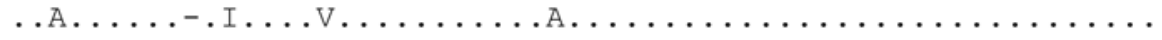 \\
\hline LV-143pl & 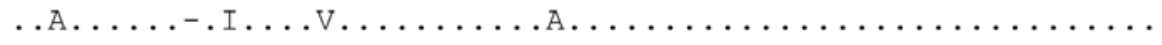 \\
\hline W3174 & 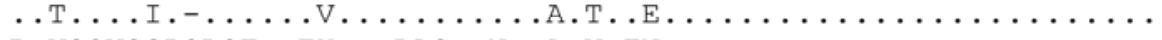 \\
\hline PENN-1 & 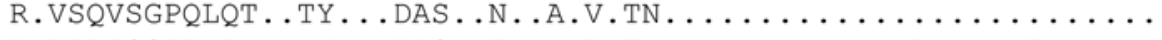 \\
\hline PS & R.VPPISGTK.R...Y...DAS .T. . V.T. . . . . . . . . . . . \\
\hline $\mathrm{BOR}-3$ & 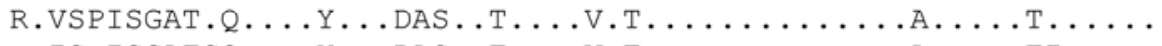 \\
\hline bTk & 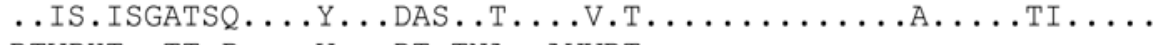 \\
\hline & TVPHT. .TT.P. . . . . . DT.TNA. .AVVRT . . . . . . . . . . . . \\
\hline
\end{tabular}

Fig. 1. Multiple alignment of the amino acid sequences of the N-terminus hypervariable region of the capsid protein (CP) of Plum pox virus (PPV)-W isolates and of representative isolates of other PPV strains. The alignment starts from the first CP amino acid. Amino acids identical to those of the LV-145pl isolate used as the reference are indicated by dots while deletions are marked by a dash. The DAG motif associated with aphid transmission (1) is marked by asterisks above the alignment. The binding site of monoclonal antibody $2 \mathrm{C} 3$ (6; see text) is boxed.

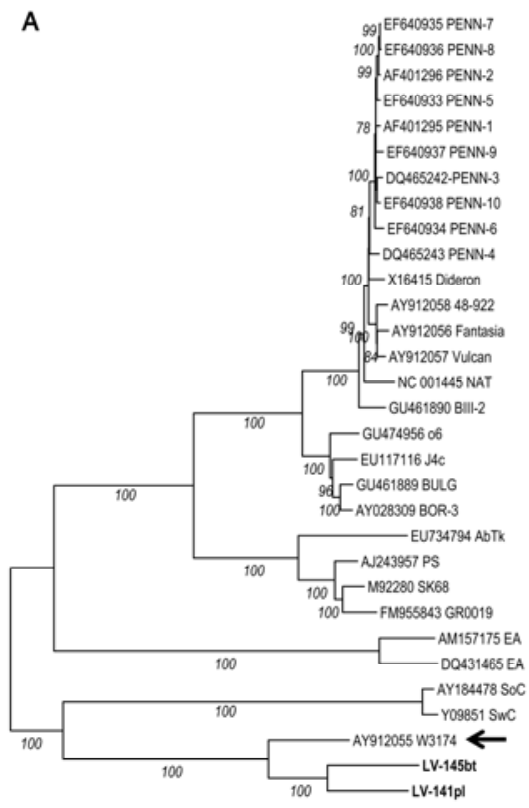

0.02

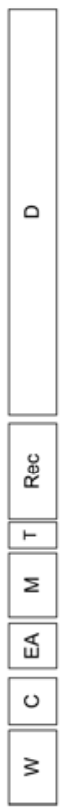

B

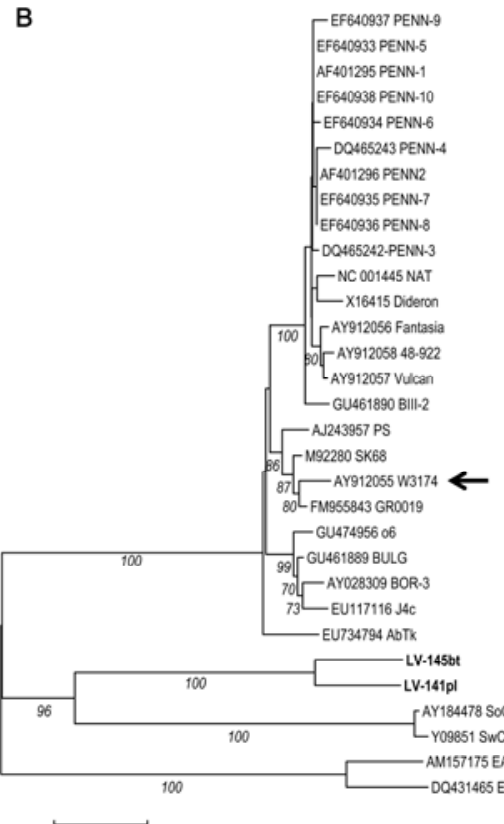

0.02
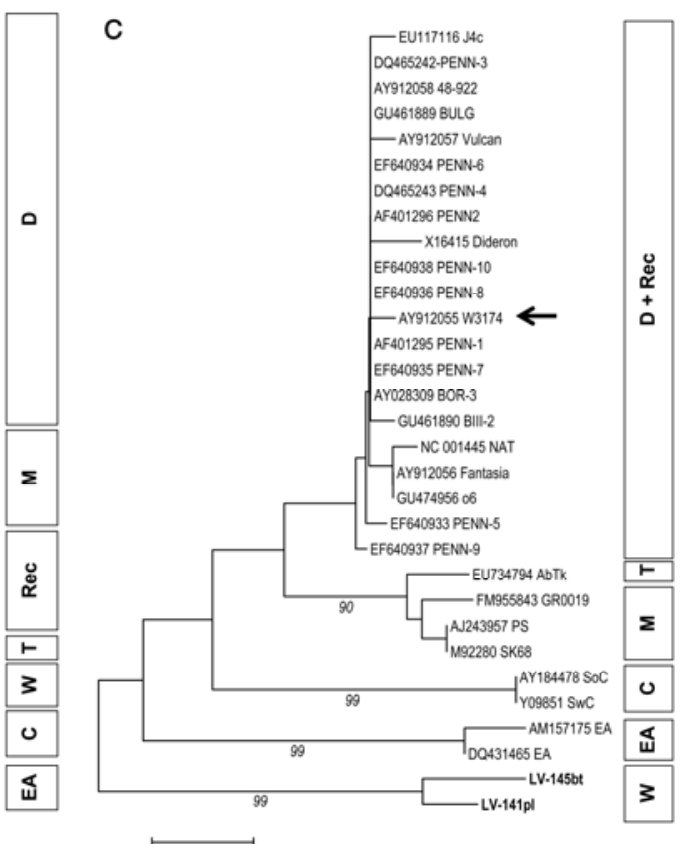

0.05

Fig. 2. Phylogenetic trees of the 31 Plum pox virus (PPV) isolates for which complete genomic sequences are available (including LV-141pl and LV-145bt, in bold). Trees were reconstructed using either $\mathbf{A}$, the complete genomic sequence; $\mathbf{B}$, the sequence of the recombined fragment in the P1/HC-Pro region (nucleotides 692 to 1424; or $\mathbf{C}$, that of the recombined fragment in the NIa (VPg) region (nucleotides 5,672-5,789). All trees were constructed by the neighbor-joining method, using Kimura two-parameter genetic distances. Scale bars represent 0.02 (A and B) or 0.05 (C) substitutions per site. Bootstrap values (only values $>70 \%$, 500 bootstrap resamplings) are indicated as percentages on branches. Arrows indicate the positions of the W3174 isolate within each tree. The affiliation of isolates to different PPV strains is indicated on the right of each tree. Due to the lower number of informative sites, D and Rec isolates are grouped within the same cluster in C. 
mental Figure 1) shows that isolates LV-140pl, LV-141pl, and LV$143 \mathrm{pl}$ are extremely closely related but that they differ significantly from the LV-145bt or W3174 isolates.

The alignment of LV141pl and LV-145bt genome has revealed that they share $94.3 \%$ identity at the nucleotide level (556 polymorphic sites). The most variable regions are in the $6 \mathrm{~K} 1, \mathrm{P} 1$, and 5 ' untranslated region. The deduced amino acid sequences of both polyproteins are $97.7 \%$ identical.

The W3174 isolate shared 93.1 and $92.1 \%$ nucleotide sequence identity with LV-141pl and LV-145bt, respectively. The corresponding nucleotide identity values with other PPV isolates reached 79.8 to $79.9 \%$ (PPV-C), 78.2 to $78.6 \%$ (PPV-D strain), 78.2 to $78.4 \%$ (PPV-Rec), 78.3 to $78.4 \%$ (PPV-M), 78.3\% (PPV$\mathrm{T}$ ), and 77.8 to $77.9 \%$ (PPV-EA). Analysis of the phylogenetic relationship using whole-genome sequences confirmed that LV$141 \mathrm{pl}, \mathrm{LV}-145 \mathrm{bt}$, and W3174 cluster together in a phylogenetically distinct group with 100\% bootstrap support (Fig. 2A).

Analysis of phylogenetic trees reconstructed from complete genome sequences (Fig. 2A) or $\mathrm{C}$-ter $\mathrm{NIb} / \mathrm{N}$-ter $\mathrm{CP}$ sequences tends to indicate a higher variability within the PPV-W strain than in any other recognized PPV strain. This possibility was evaluated by calculating intrastrain genetic diversity (average pairwise divergence) for both regions, using all sequences available in GenBank for each strain. The results indicated that PPV-W genetic diversity is, indeed, two to eight times higher than those of other PPV strains when considering complete genomic sequences (Table 1). The number of complete genomes available for intrastrain comparison is low (with the exception of the PPV-D strain) but a similarly higher diversity for PPV-W (three to fourfold) is observed with larger numbers of sequences in the C-ter $\mathrm{NIb} / \mathrm{N}$-ter $\mathrm{CP}$ region (Table 1 ).

The variability between the LV-145bt or LV-141pl and W3174 isolates is not evenly distributed along the entire genome, and two peaks of variability (both $>20 \%$ divergence) are apparent in the P1/HC-Pro and N-ter (VPg portion) of the NIa regions (Fig. 3A). The first of these regions was previously identified as involved in a potential recombination event in the case of W3174 (positions 801 to 1450) (22). To elucidate the origin of such a striking variation pattern, a search for potential recombination events was performed using the Phylpro program (33) using the complete sequences of LV-145bt (or LV-141pl), W3174, and representative isolates of the PPV-D and M strains. Although clear recombination signals were observed at the borders of the highly divergent regions between LV-145bt and W3174 (Fig. 3C), such signals were no longer observed when excluding W3174 from the analysis (Fig. 3D). This strongly suggested that, in addition to the previously identified P1/HC-Pro recombination event, W3174 might also have recombined in the VPg region. It also suggested that LV-145bt and LV-141pl are probably not recombinant in nature.

TABLE 1. Within-strain genetic diversity (Kimura two-parameter distance) calculated for all seven Plum pox virus (PPV) strains using either complete genomic sequences or a shorter sequence encoding the capsid protein $(\mathrm{CP}) \mathrm{N}$ terminal (N-ter) hypervariable region

\begin{tabular}{lll}
\hline Strain & Complete genome $^{\mathrm{a}}$ & \multicolumn{1}{c}{ (N-ter $)$ CP region $^{\mathrm{b}}$} \\
\hline W & $0.072( \pm 0.003), n=3$ & $0.064( \pm 0.009), n=5$ \\
EA & $0.039( \pm 0.002), n=2$ & $0.022( \pm 0.006), n=2$ \\
M & $0.020( \pm 0.001), n=3$ & $0.015( \pm 0.003), n=31$ \\
Rec & $0.016( \pm 0.001), n=4$ & $0.016( \pm 0.003), n=25$ \\
D & $0.010( \pm 0.000), n=16$ & $0.020( \pm 0.003), n=50$ \\
C & $0.009( \pm 0.001), n=2$ & $0.024( \pm 0.008), n=2$ \\
T & n/a, $n=1$ & $0.023( \pm 0.005), n=5$ \\
\hline
\end{tabular}

${ }^{a}$ Average pairwise distances (diversity) are shown, with standard deviations in parentheses. The number of sequences available for the analysis for each strain $(n)$ is also shown; $\mathrm{n} / \mathrm{a}=$ does not apply.

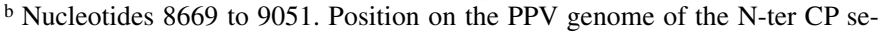
quence used is indicated, based on the numbering of the complete sequence of the LV-145bt isolate.
This possibility was further analyzed by first identifying (using Phylpro and analysis of multiple alignments) the potential borders of recombination events and then performing phylogenetic analyses separately for those genomic fragments suspected to have undergone recombination in W3174 (Fig. 2B and C). According to the Phylpro program, the two W3174 putative recombination events have break points around positions 692 to 1424 and 5672 to 5789 , respectively. Analysis of the phylogenetic tree constructed for the $\mathrm{P} 1 / \mathrm{HC}$-Pro region confirms that W3174 is closely related in that region with isolates belonging to the PPV-M strain (Fig. 2B). On the other hand, phylogenetic analysis using the fragment corresponding to positions 5672 to 5789 in the VPg gene shows that W3174 is almost identical in this region with isolates belonging to the PPV-D strain (Fig. 2C). These results indicated that isolate W3174 has a genome with a mosaic structure resulting from two recombination events involving a PPV-M isolate in the P1/HC-Pro region and a PPV-D isolate in the VPg one. In contrast, the LV141pl and LV-145bt isolates do not appear to have been affected by recombination events and, therefore, may be considered as representative of the "ancestral" PPV-W genome. This analysis is strengthened by partial nucleotide sequencing of isolate $\mathrm{LV}-140 \mathrm{pl}$ in the $\mathrm{P} 1 / \mathrm{HC}-\mathrm{Pro}$ and $\mathrm{VPg}$ regions (accession

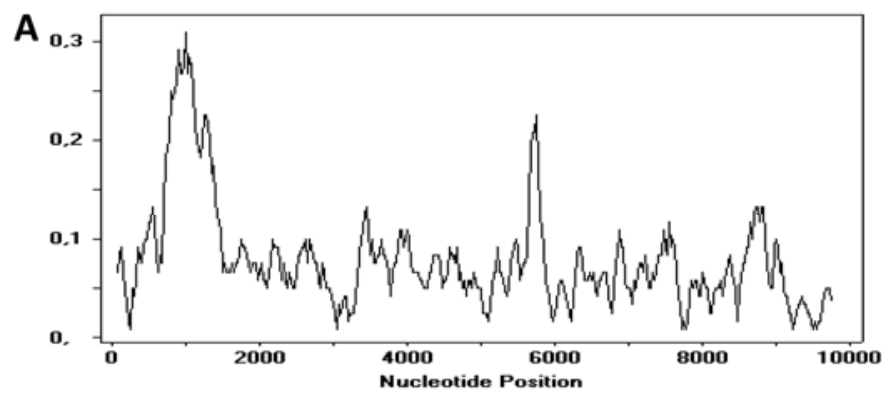

B

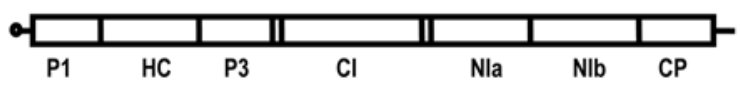

C

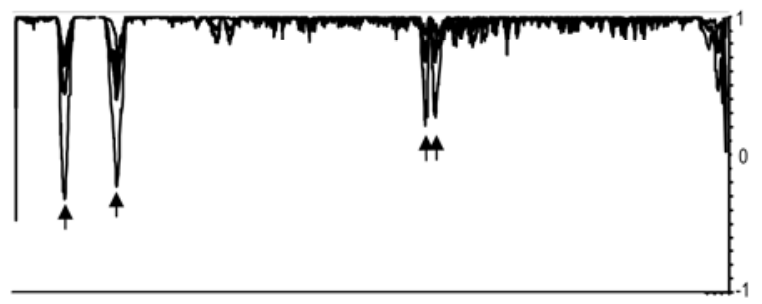

D

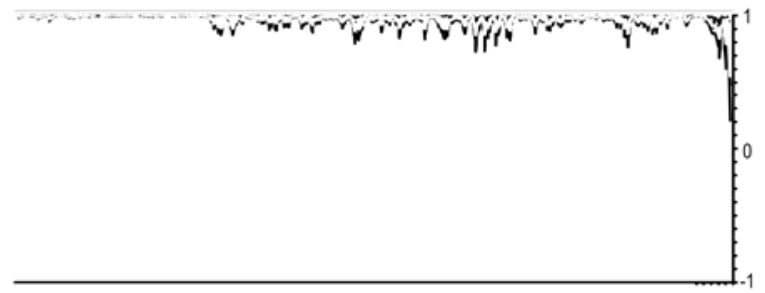

Fig. 3. Diversity and recombination analysis along the Plum pox virus (PPV)W3174 and LV-145bt genomes. A, Nucleotide diversity index between the aligned W3174 and LV-145bt genomic sequences, calculated along the genome using DnaSP software with a sliding window of 100 nucleotides (nt) moved by steps of $25 \mathrm{nt}$. B, Schematic representation of the PPV genome. Names of the various mature viral proteins are indicated below. Analysis of recombination events using the PhylPro program and the full-length genomic sequences of isolates C, W3174, LV-145bt, Fantasia (PPV-D), and PS (PPV$\mathrm{M})$ or D, LV-145bt, Fantasia, and PS. Peaks in C pinpoint the recombination signals in the W3174 genome around nucleotide positions 692, 1424, 5672, and 5789, respectively. The Y-axis gives the phylogenetic correlation on a default axis of -1 to 1 . 
number HQ670745), which showed a high level of identity with the LV-141pl and LV-145bt sequences and an absence of the recombination events which characterize W3174 (data not shown).

A multiple-sequence alignment of the NIb-CP region of W3174 and of the four Latvian isolates analyzed in this study was used to design PPV-W-specific primers (Fig. 4). In controls assays, no amplification product was generated from PPV isolates belonging to the PPV-M, -D, -Rec, -T, -EA, and -C strains whereas the expected product was readily amplified from all five PPV-W isolates assayed. The GC content of these new primers and the size of the amplified product ( 381 to $384 \mathrm{bp}$ ) allow the use the same cycling conditions as for the universal P1/P2 primers (34). The RT-PCR assay was optimized and gave the same results whether total RNAs isolated from original Prunus leaves or genomic RNA released from denatured immunocaptured particles were used for cDNA synthesis. The specificity of the amplified products was validated by direct sequencing.

\section{DISCUSSION}

The PPV-W strain was recognized only recently (14) and only one isolate, W3174, had so far been available for study. The identification of four new isolates (found in two Prunus spp.) belonging to the PPV-W strain has allowed a first analysis of the variability of this poorly known strain. Although the W3174 isolate was initially discovered in Canada, it is likely that this was not the country of its origin. In a similar fashion, despite the fact that the new PPV-W isolates analyzed here were identified in Latvia, the original focus of PPV-W is probably not in Latvia. First, partial sequence analysis of 18 other PPV isolates collected from different parts in Latvia (Aizkraukle, Dobele, Balvi, and Pure) showed only the presence of PPV-D isolates (data not shown). Second, the cultivars in which the new PPV-W isolates were observed are not autochthonous to Latvia but were introduced $\approx 20$ years ago from former Soviet Union countries (Russia and Ukraine), suggesting that the original dissemination focus may originate from this area. Such a hypothesis is in line with recent reports of PPV-W isolates from Ukraine and Russia $(19,29)$. The variability observed among the four Latvian PPV-W isolates suggests that at least two independent introductions took place, corresponding to LV-145bt and to LV-140pl, LV-141pl, and LV-143pl (Fig. 1).
Sequence comparisons indicate a surprisingly high level of variability within the PPV-W strain. Indeed, despite the low number of sequences available for PPV-W, this variability appears to be at least twice that of the second most variable strain, PPV-EA (Table 1), and several fold that of the more widespread PPV-D, PPV-M, or PPV-Rec strains. This observation raises the question of the reason for this higher variability of minor strains as compared with their more widespread counterparts. A possibility could be that the more widespread PPV strains have a higher fitness or a greater epidemic potential. This, in turn, would result in the wide diffusion of a higher number of PPV genotypes through uncontrolled exchange of propagation material. Such a situation appears, for example, to characterize the recent outbreaks of PPV in the United States, Canada, or Chile $(16,26,30,31)$.

Whereas the LV-141pl and LV-145bt isolates (and very likely the other PPV-W Latvian isolates) appear to represent the ancestral PPV-W strain, unaffected by a recombination event, the results presented here show that isolate W3174 is chimeric and not typical of other PPV-W isolates. In fact, W3174 is the first PPV isolate known to involve three PPV strains in its ancestry (i.e., PPV-W, PPV-M, and PPV-D). The results of the Phylpro and phylogenetic analyses performed here indicate that the left border of the recombination event affecting the P1/HC-Pro region is close to position 692, at slight variance from the original report which suggested a breakpoint close to position 801 (22). Recombination events at various positions in this region have also been reported for isolates belonging to the PPV-T and to the PPV-D or -M strains (11). On the other hand, the recombination event affecting the VPg region had never been detected previously. The small size of the recombined fragment $(\approx 110$ to $120 \mathrm{nt})$ might explain why it had not be detected before. An alternative to this recombination scenario would explain the very high local homology between W3174 and isolates belonging to the PPV-D strain by convergent evolution resulting from a selection pressure acting on the VPg protein. This alternative hypothesis is, however, not supported by the observation that most of the differences between W3174 and the two completely sequenced Latvian isolates in that region are noncoding (not shown).

The partial sequencing of the four Latvian isolates in the $\mathrm{CP}$ $\mathrm{N}$-ter hypervariable region revealed significant variability between PPV-W isolates in this region (Fig. 1). Such variability might have significant implications for the serological detection of PPV-W

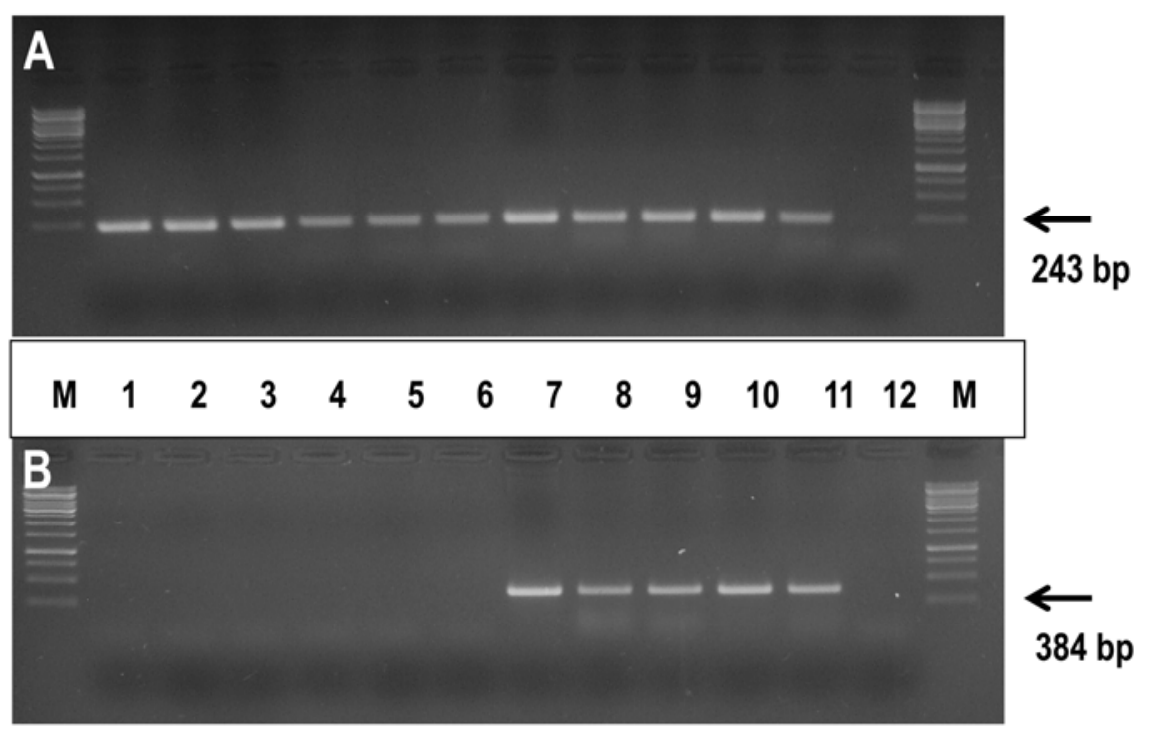

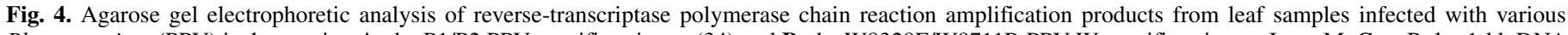

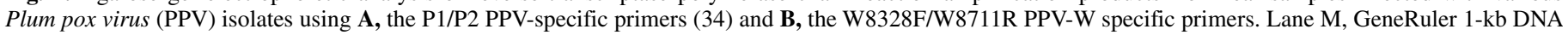

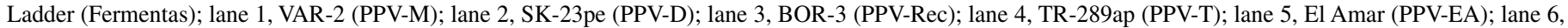

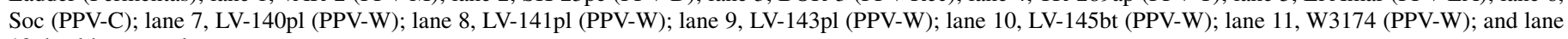
12 , healthy control. 
isolates. In particular, monoclonal antibody (MAb) $2 \mathrm{C} 3$ has been developed and proposed as a valuable PPV-W-specific detection reagent (6). Mapping of the binding site of this MAb using synthetic peptides has revealed that it binds the W3174-derived peptide DEEDDDPTIV, which corresponds to positions 2 to 11 of the $\mathrm{CP}$. MAb $2 \mathrm{C} 3$ binding was also shown to be affected by mutations at positions 4 and 8 to 10 (three simultaneous mutations at these three positions) (6). Analysis of the CP sequences for the Latvian isolates shows that they differ from W3174 by several mutations in this region: D2N, P8S, and either $\mathrm{I} 10 \mathrm{~V}$ or, in the case of LV-145bt, by deletion of I10. In particular, the mutations affecting positions 8 and 10 are very likely to affect the binding of this MAb and compromise its potential as a PPVW-specific MAb (20). This analysis is confirmed by the observation that MAb 2C3 does not show reactivity toward the four PPV-W isolates from Latvia (T. Malinowski, unpublished data). To overcome this problem and to develop a tool for the specific diagnostic of PPV-W isolates, a specific primer pair was designed and successfully used in an RT-PCR assay which can be used for the rapid identification of PPV-W isolates.

The results presented here further our understanding of the molecular variability of the PPV-W strain and of its evolutionary history. They also show that isolates LV141pl and LV-145bt should probably be considered as representing "typical" PPV-W isolates rather than W3174. In addition, the identification of these new PPV-W isolates shed light on its probable area of origin and open the way for the biological and epidemiological characterization of this thus far very poorly known PPV strain.

\section{ACKNOWLEDGMENTS}

This work was supported by the European Union through the FP7 Small Collaborative Project KBBE-204429 (SHARCO) and partially by the grants APVV-51-0402-07 from the Slovak Research and Development Agency, VEGA 2/0027/09 from the Scientific Grant Agency of the Ministry of Education and Slovak Academy of Sciences, and ESF project number 2009/0228/1DP/1.1.1.2.0/09/APIA/VIAA/035. We thank J. Mihailova (State Plant Protection Service, Riga, Latvia) for helpful collaboration, D. James (CFIA Sidney, Canada) for providing the W3174 isolate, C. Ulubas-Serce (Mustafa Kemal University, Hatay, Turkey) and G. Labonne (INRA Montpellier, France) for supplying the PPV-T and PPV-C isolates, and G. Labonne for the generous gift of the AS196 PPV antiserum.

\section{LITERATURE CITED}

1. Atreya, P. L., Lopez-Moya, J. J., Chu, M., Atreya, C. D., and Pirone, T. P. 1995. Mutational analysis of the coat protein N-terminal amino acids involved in potyvirus transmission by aphids. J. Gen. Virol. 76:265-270.

2. Cambra, M., Capote, N., Myrta, A., and Llacer, G. 2006. Plum pox virus and the estimated costs associated with Sharka disease. Bull. OEPP/EPPO Bull. 36:202-204.

3. Candresse, T., and Cambra, M. 2006. Causal agent of Sharka disease: historical perspective and current status of Plum pox virus strains. Bull. OEPP/EPPO Bull. 36:239-246.

4. Candresse, T., Cambra, M., Dallot, S., Lanneau, M., Asensio, M., Gorris, M. T., Revers, F., Macquaire, G., Olmos, A., Boscia, D., Quiot, J. B., and Dunez, J. 1998. Comparison of monoclonal antibodies and polymerase chain reaction assays for the typing of isolates belonging to the $\mathrm{D}$ and $\mathrm{M}$ serotypes of Plum pox potyvirus. Phytopathology 88:198-204.

5. Cervera, M. T., Riechmann, J. L., Martin, M. T., and Garcia, J. A. 1993. 3' Terminal sequence of the plum pox virus PS and o6 isolates: Evidence for RNA recombination within the potyvirus group. J. Gen. Virol. 74:329-334.

6. Croft, H., Malinowski, T., Krizbai, L., Mikec, I., Kajic, V., Reed, C., Varga, A., and James, D. 2008. Use of Luminex xMAP-derived Bio-Plex bead-based suspension array for specific detection of PPV W and characterization of epitopes on the coat protein of the virus. J. Virol. Methods 153:203-213.

7. Elena, S. F., Agudelo-Romero, P., Carrasco, P., Codoner, F. M., Martin, S., Torres-Barcelo, C., and Sanjuan, R. 2008. Experimental evolution of plant RNA viruses. Heredity 100:478-483.

8. Garcia-Arenal, F., Fraile, A., and Malpica, J. M. 2001. Variability and genetic structure of plant virus populations. Annu. Rev. Phytopathol. 39:157-186.

9. Garcia-Arenal, F., Fraile, A., and Malpica, J. M. 2003. Variation and evolution of plant virus populations. Int. Microbiol. 6:225-232.

10. Garcia, J. A., and Cambra, M. 2007. Plum pox virus and Sharka disease. Plant Viruses 1:69-79.

11. Glasa, M., and Candresse, T. 2005. Partial sequence analysis of an atypical Turkish isolate provides further information on the evolutionary history of Plum pox virus (PPV). Virus Res. 108:199-206.

12. Glasa, M., Marie-Jeanne, V., Labonne, G., Subr, Z., Kudela, O., and Quiot, J. B. 2002. A natural population of recombinant Plum pox virus is stable and competitive under field conditions. Eur. J. Plant Pathol. 108:843-853.

13. Glasa, M., Palkovics, L., Kominek, P., Labonne, G., Pittnerova, S., Kudela, O., Candresse, T., and Subr, Z. 2004. Geographically and temporally distant natural recombinant isolates of Plum pox virus (PPV) are genetically very similar and form a unique PPV subgroup. J. Gen. Virol. 85:2671-2681.

14. James, D., and Varga, A. 2005. Nucleotide sequence analysis of Plum pox virus isolate W3174: evidence of a new strain. Virus Res. 110:143-150.

15. Kumar, S., Dudley, J., Nei, M., and Tamura, K. 2008. MEGA: A biologistcentric software for evolutionary analysis of DNA and protein sequences. Brief. Bioinf. 9:299-306.

16. Levy, L., Damsteegt, V., and Welliver, R. 2000. First report of Plum pox virus (Sharka disease) in Prunus persica in the United States. Plant Dis. 84:202.

17. Librado, P., and Rozas, J. 2009. DnaSP v5: a software for comprehensive analysis of DNA polymorphism data. Bioinformatics 25:1451-1452.

18. López-Moya, J. J., Fernandez-Fernandez, M. R., Cambra, M., and García, J. A. 2000. Biotechnological aspects of Plum pox virus. J. Biotechnol. 76:121-136.

19. Mavrodieva, V., Mock, R., and Levy, L. 2006. Molecular characterization of PPV isolates from plum germplasm illegally imported from Ukraine. Page 112 in: Book of Abstracts, 20th International Symposium on Virus and Virus-like Diseases of Temperate Fruit Crops Antalya, Turkey.

20. Mavrodieva, V., Negi, S., James, D., and Levy, L. 2010. Sequence variability among isolates of strain $\mathrm{W}$ of Plum pox virus (PPV) influences identification. Page 14 in: Book of Abstracts, International Symposium on Plum pox virus, Sofia, Bulgaria.

21. Moury, B., Desbiez, C., Jacquemond, M., and Lecoq, H. 2006. Genetic diversity of plant virus populations: towards hypothesis testing in molecular epidemiology. Adv. Virus Res. 67:49-87.

22. Myrta, A., Varga, A., and James, D. 2006. The complete genome sequence of an El Amar isolate of Plum pox virus (PPV) and its phylogenetic relationship to other PPV strains. Arch. Virol. 151:1189-1198.

23. Nemchinov, L., and Hadidi, A. 1996. Characterization of the sour cherry strain of Plum pox virus. Phytopathology 86:575-580.

24. Posada, D. 2002. Evaluation of methods for detecting recombination from DNA sequences: empirical data. Mol. Biol. Evol. 19:708-717.

25. Revers, F., Le Gall, O., Candresse, T., Le Romancer, M., and Dunez, J. 1996. Frequent occurrence of recombinant potyvirus isolates. J. Gen. Virol. 77:1953-1965.

26. Reyes, F., Fiore, N., Reyes, M. A., Sepulveda, P., Paredes, V., and Prieto, H. 2003. Biological behavior and partial molecular characterization of six Chilean isolates of Plum pox virus. Plant Dis. 87:15-20.

27. Roosinck, M. J. 1997. Mechanism of plant virus evolution. Annu. Rev. Phytopathol. 35:191-205.

28. Serce, C. U., Candresse, T., Svanella-Dumas, L., Krizbai, L., Gazela, M., and Caglayan, K. 2009. Further characterization of a new recombinant group of Plum pox virus isolates, PPV-T, found in orchards in the Ankara province of Turkey. Virus Res. 142:121-126.

29. Sheleva, A., Nemova, E., and Chirkov, S. 2010. Detection of an unusual isolate of Plum pox virus in plum (Prunus nigra). Page 16 in: Book of Abstracts, International Symposium on Plum pox virus, Sofia, Bulgaria.

30. Thompson, D., McCann, M., MacLeod, M., Lye, D., Green, M., and James, D. 2001. First report of Plum pox potyvirus in Ontario, Canada. Plant Dis. 85:97.

31. Thompson, D., Varga, A., De Costa, H., Birch, C., Glasa, M., and James, D. 2009. First report of Plum pox virus recombinant strain on Prunus spp. in Canada. Plant Dis. 93:674.

32. Urcuqui-Inchima, S., Haenni, A. L., and Bernardi, F. 2001. Potyvirus proteins: a wealth of functions. Virus Res. 74:157-175.

33. Weiller, G. F. 1998. Phylogenetic profiles: a graphical method for detecting genetic recombinations in homologous sequences. Mol. Biol. Evol. 15:326-335.

34. Wetzel, T., Candresse, T., Ravelonandro, M., Delbos, R. P., Mazyad, H., Aboul-Ata, A. E., and Dunez, J. 1991. Nucleotide sequence of the 3'terminal region of the RNA of the El Amar strain of plum pox potyvirus. J. Gen. Virol. 72:1741-1746.

35. Worobey, M., and Holmes, E. C. 1999. Evolutionary aspects of recombination in RNA viruses. J. Gen. Virol. 80:2535-2543. 